\title{
Photoluminescence from Divalent Europium Ion Doped in Silica Glass Prepared with Sol-Gel Technique*
}

Yukon Murakami and Yutaka Kawabe ${ }^{\dagger}$

Chitose Institute of Science and Technology, Chitose 066-8655, Japan

(Received 26 December 2014; Accepted 3 February 2015; Published 21 February 2015)

\begin{abstract}
Europium ions were doped in silica glass matrix with a sol-gel method as well as Al co-dopant. The samples densified at $1050^{\circ} \mathrm{C}$ showed bright blue emission under UV illuminations. Lifetime of the luminescence was about $1 \mu \mathrm{s}$ and did not depend on $\mathrm{Al}$ concentration, indicating that europium existed as divalent form at proximate positions to aluminum ions. [DOI: 10.1380/ejssnt.2015.51]
\end{abstract}

Keywords: Photoluminescence; Silicon oxides; Lanthanides; Sol-gel glass; Divalent europium; Time-resolved spectroscopy

\section{INTRODUCTION}

Broad luminescence from divalent europium ion $\left(\mathrm{Eu}^{2+}\right)$ is promising for the application to phosphors for white light illumination and solid-sate laser devices $[1,2]$. The ion shows $d-f$ transition which is advantageous for tunable stimulated emission due to its large oscillator strength, broad emission width, and wavelength variation by host, contrary to the narrow emission by $f-f$ transitions with fixed wavelengths in trivalent counterpart [3]. Considering charge balance in a matrix, divalent Eu could be preferably located at the sites of divalent ions, such as $\mathrm{Ba}, \mathrm{Sr}, \mathrm{Ca}$ and $\mathrm{Mg}[2,4,5]$. However, there have been several studies showing blue photoluminescence assumingly caused by $\mathrm{Eu}^{2+}$ ions doped in silica matrix formed with sol-gel process without any reducing procedure [6-9]. The mechanism for $\mathrm{Eu}^{2+}$ formation in silica has not been well understood yet, but the emission was found to be usually enhanced with co-doping of aluminum ions. In this study, we prepared silica glass doped with Eu and Al by a conventional sol-gel method, and investigated the dynamical properties of the excited state with a time-resolved photoluminescence spectroscopy in order to elaborate the dependence on $\mathrm{Al}$ concentration which would be a clue for the emission mechanism.

\section{EXPERIMENTAL}

In this study, we synthesized sol-gel silica glass containing europium and co-dopant aluminum with a conventional sol-gel process $[10,11]$. Tetramethylorthosilicate (TMOS) diluted with dimethylformamide (DMF) was hydrolyzed by acidic water mixed with methanol. Prescribed amounts of europium nitrate hexahydrate and aluminum nitrate nonahydrate were previously dissolved in the water. Typical amounts of starting materials were 30, 15, 15, and $38 \mathrm{ml}$ for TMOS, DMF, methanol, and water, respectively. Hydrochloric acid was employed as a catalyst by making the water contain $\mathrm{HCl}$ of nominally $1 \times 10^{-3} \mathrm{~mol} / \mathrm{l}$. Concentration of europium was $0.1 \%$ of silicon atom, and that of aluminum was varied in the range

\footnotetext{
* This paper was presented at the 15th Chitose International Forum "Nanotechnology - From Synthesis to Devices," Chitose Institute of Science and Technology, Chitose, Japan, October 2-3, 2014.

$\dagger$ Corresponding author: y-kawabe@photon.chitose.ac.jp
}

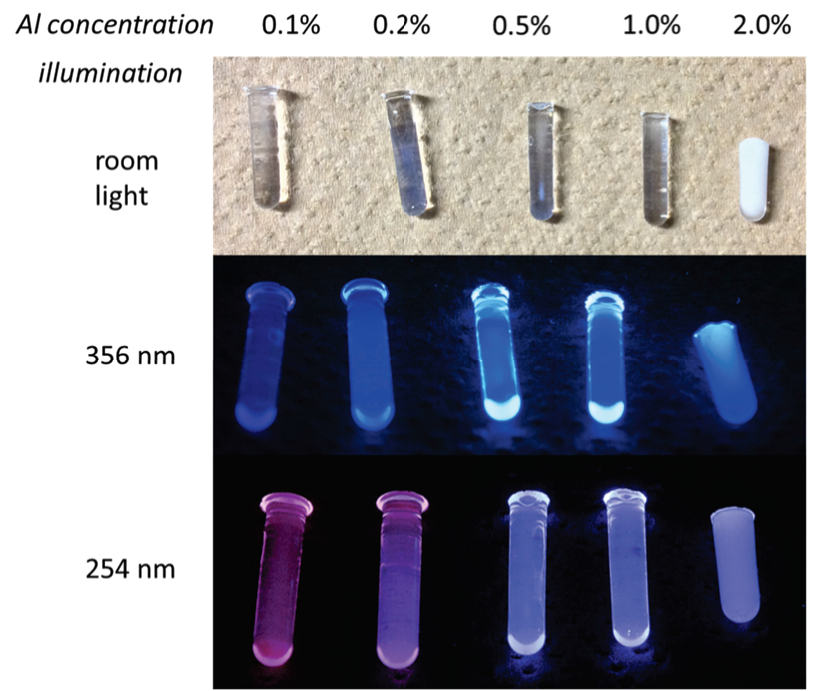

FIG. 1. Silica glass rods containing $\mathrm{Al}$ and Eu prepared with sol-gel method observed under room light or UV illumination.

of $0.1 \sim 2.0 \%$. Each $4 \mathrm{ml}$ portion of final mixture was kept at $80^{\circ} \mathrm{C}$ for a week in a polymethylpentene (TPX) test tube, giving a rod-shaped monolith with $1.0 \mathrm{~g}$ weight. By continuous heating at $100 \sim 110^{\circ} \mathrm{C}$ for about 3 weeks, the monolith weight reduced to $0.75 \mathrm{~g}$, being well for final densification. Then the dried rods were heated up to $1050^{\circ} \mathrm{C}$ with the rate of $32^{\circ} \mathrm{C} / \mathrm{h}$ and were kept for $8 \mathrm{~h}$ at $1050^{\circ} \mathrm{C}$. All the processes were done in air atmosphere. We also made samples doped with only $\mathrm{Al}$ or $\mathrm{Eu}$ ion for comparison.

Photoluminescence (PL) properties were studied by conventional fluorescence spectrometer measuring emission and excitation spectra. Time resolved PL spectra were obtained with an ICCD-equipped spectrometer with the excitation by the third harmonics of a Q-switched $\mathrm{Nd}^{3+}$ YAG laser. Nominal temporal resolution was 2 ns.

\section{RESULTS AND DISCUSSION}

All prepared samples gave bright PL under the illumination of a mercury lamp with wavelength of $254 \mathrm{~nm}$ or $365 \mathrm{~nm}$. As shown in Fig. 1, high concentration of the codopant enhanced the emission intensity. More purplish color under the deep UV was a result from emission in 


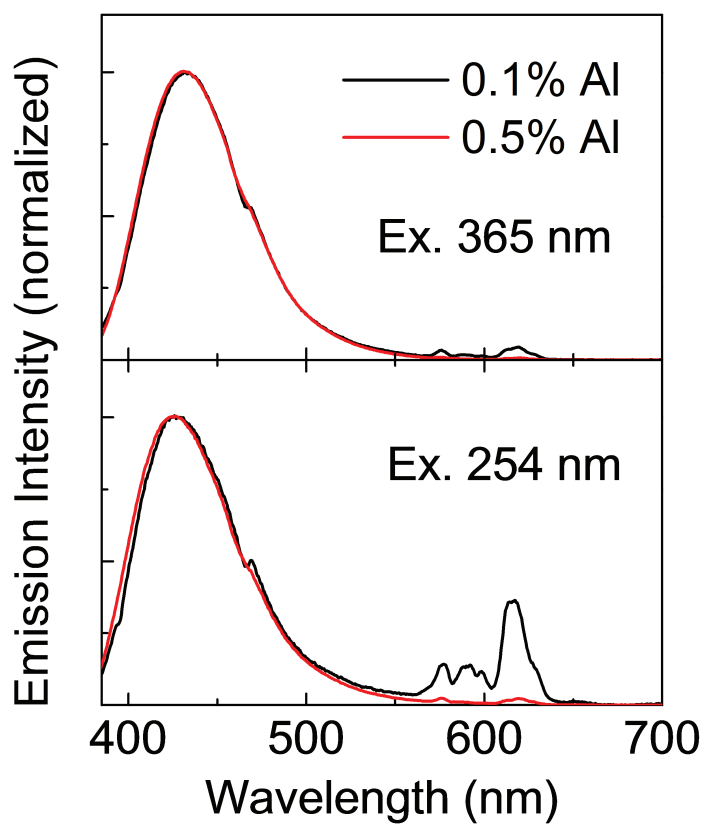

FIG. 2. Photoluminescence spectra for glass samples doped with $\mathrm{Eu} 0.1 \%$ and $\mathrm{Al} 0.1$ or $0.5 \%$ under the excitation at 365 and $254 \mathrm{~nm}$.

both blue and red wavelength regions, contrary to purer blue color under the $365 \mathrm{~nm}$ excitation as confirmed in PL spectra depicted in Fig. 2. There was no remarkable dependence of emission spectrum on co-dopant concentration for the main peak. Although weak emission corresponding to $\mathrm{Eu}^{3+}$ was observed in longer wavelength side for the sample with less concentrated Al, strong blue and broad emission suggested that divalent state was dominant in the matrix.

The samples doped with only $\mathrm{Eu}$ or $\mathrm{Al}$ did not show any emission in blue region. Pure silica glass without any dopant was prepared with the same method giving no luminescence. Because the comparison experiments eliminated the possibility of defect sites emission, we assigned the emission in blue region to $d-f$ transition in $\mathrm{Eu}^{2+}$. The necessity of the co-dopant has been claimed by Silversmith et al., but been discussed mainly for trivalent ion emission [9]. According to their discussion, co-dopant might have enhanced the emission through the decrease of concentration quenching or increase of oscillator strength due to crystal field. It is not certain that their conclusion is applicable to the divalent case, but such effects would reflect on the lifetime of the excited state.

Therefore, we measured the PL lifetime under the excitation with the pulsed laser of $355 \mathrm{~nm}$ wavelength. Figure 3 showed the decay of luminescence intensity observed with the ICCD system for the sample with $0.1 \% \mathrm{Eu}$ and $0.5 \% \mathrm{Al}$. The result indicated single exponential decay with $1.1 \mu$ s lifetime. All other samples with different $\mathrm{Al}$ concentrations gave similar values ranging in 1.1-1.3 $\mu \mathrm{s}$. The lifetime values also supported the assignment to divalent ions, because preceding several studies on the lifetime of $\mathrm{Eu}^{2+}$ have given the values about the order of $\mu \mathrm{s}[2,4]$. On the other hand, the lifetime for red wavelength emission was about ms confirming the trivalent ion origin.

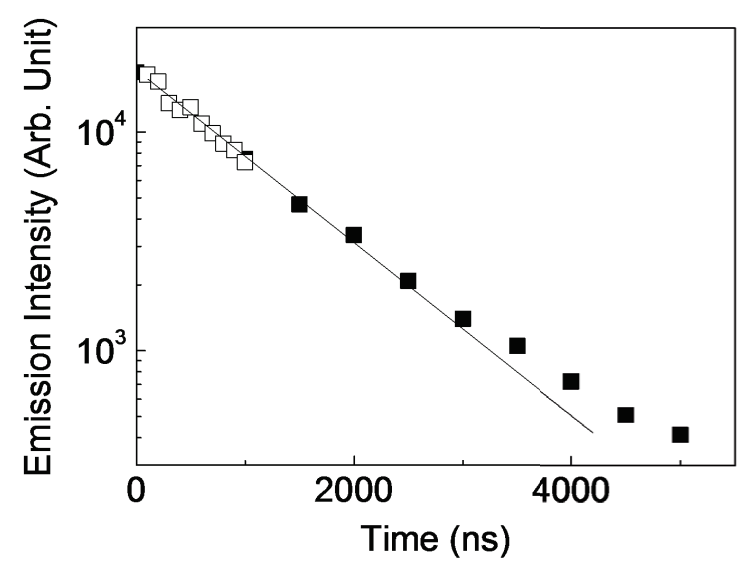

FIG. 3. Temporal decay of emission intensity after the excitation with $355 \mathrm{~nm}$ pulses for the sample containing $0.1 \% \mathrm{Eu}$ and $0.5 \% \mathrm{Al}$. Symbols indicate separate experimental runs made with different time range.

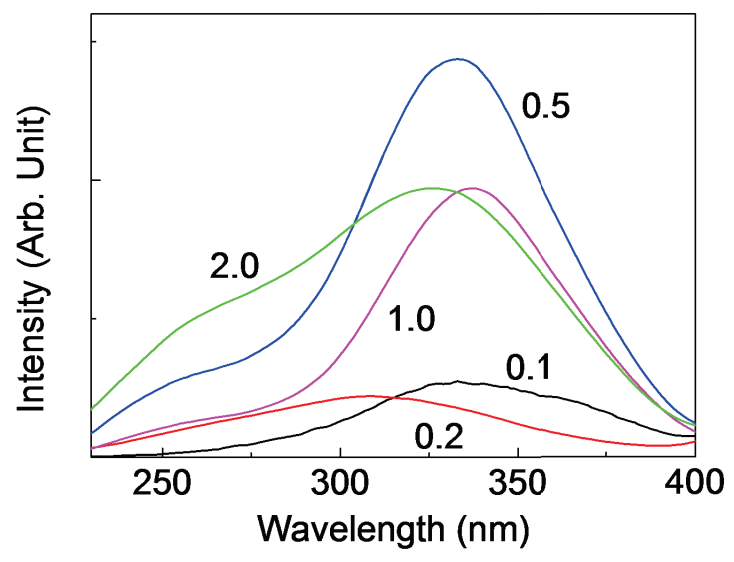

FIG. 4. Excitation spectra monitored at $430 \mathrm{~nm}$ for Eu doped sol-gel silica. Numbers indicate the concentration percentage of co-dopant Al.

The PL lifetime did not depend on $\mathrm{Al}$ concentration in spite of large variety of their intensities. Because the concentration of $\mathrm{Eu}$ was the same in all the cases, the similar lifetime suggested that divalent ions were located in similar environment but the number of emissive ions was different. In other words, the intensity would reflect the number of PL active ions. Therefore, we can conclude that europium ions only closely locating at $\mathrm{Al}$ ions emit light and others in the matrix are strongly quenched regardless of whether the ions exist as divalent or trivalent form.

Because the relative emission intensity in red wavelength region was stronger in the samples with less concentrated aluminum, europium ions surrounded by silicarich part of the matrix would exist as the trivalent form. However, the ratio and distribution of $\mathrm{Eu}^{2+}$ and $\mathrm{Eu}^{3+}$ seem to be very sensitive to the preparation method, because some preceding results gave relatively strong red emission.

Excitation spectra monitored at wavelength $430 \mathrm{~nm}$ 
gave a main peak at $330 \mathrm{~nm}$ and a shoulder at $260 \mathrm{~nm}$ as shown in Fig. 4, and also showed dependence on the $\mathrm{Al}$ concentration. The two peaks reflected sub-band structure determined by crystal field at the center of octahedron typically observed in $\mathrm{Ce}^{3+}[12]$. However, we could not find any systematic dependence on the concentration, as known from the figure. It could be a tool for the investigation of local environment for divalent ions, although we leave it for future studies.

\section{CONCLUSIONS}

$\mathrm{Eu}$ and Al doped silica glass was prepared with a solgel method, showing bright blue PL under UV light excitation. Origin of the emission was confirmed to be $d-$ $f$ transition in divalent europium ions by time-resolved photoluminescence study. Dependence on Al concentration indicated that divalent ions only closely locating at $\mathrm{Al}$ ions could emit light otherwise were quenched.
[1] W. M. Yen and M. J. Weber, Inorganic phosphors (CRC, Boca Raton, 2004).

[2] S. H. M. Poort, A. Meyerink, and G. Blasse, J. Phys. Chem. Solids 58, 1451 (1997).

[3] B. Henderson and G. F. Imbusch, Optical spectroscopy of inorganic solids (Clarendon, Oxford, 1989).

[4] T. Tsuboi and P. Silfsten, J. Phys. Condens. Matters 3, 9163 (1991).

[5] Y.-S. Tang, S.-F. Hu, C. C. Lin, N. C. Bagkar, and R.-S. Liu, Appl. Phys. Lett. 90, 151108 (2007).

[6] M. Nogami, T. Yamazaki, and Y. Abe, J. Lumin. 78, 63 (1998).
[7] N. Kamata, C. Satoh, K. Tosaka, and K. Yamada, J. NonCryst. Solids 293-295, 595 (2001).

[8] N. Kamata, K. Tosaka, Z. Honda, and K. Yamada, Jpn. J. Appl. Phys. 43, L372 (2004).

[9] A. J. Silversmith, A. P. Beyler, K. E. Arpino, D. M. Boye, and K. R. Hoffman, J. Lumin. 131, 457 (2011).

[10] T. Adachi and S. Sakka, J. Non-Cryst. Solids 99, 118 (1988).

[11] T. Adachi and S. Sakka, J. Non-Cryst. Solids 100, 250 (1988).

[12] P. Dorenbos, J. Lumin. 91, 91 (2000). 